\title{
WebLab for measuring the attenuation coefficient of an optical fiber
}

Sérgio Szpigel, Eunézio de Souza, Fábio Paschoal, Erik Antonio, Joaquim Filho

Sérgio Szpigel, Eunézio A. de Souza, Fábio Paschoal Jr., Erik A. Antonio, Joaquim P. Filho, "WebLab for measuring the attenuation coefficient of an optical fiber," Proc. SPIE 9665, Tenth International Topical Meeting on Education and Training in Optics and Photonics, 96650Y (3 June 2007); doi: $10.1117 / 12.2207344$

SPIE Event: Tenth International Topical Meeting on Education and Training in Optics and Photonics, 2007, Ottawa, Ontario, Canada 


\title{
WebLab for Measuring the Attenuation Coefficient of an Optical Fiber
}

\author{
Sérgio Szpigel \\ Centro de Ciências e Humanidades, Universidade Presbiteriana Mackenzie, São Paulo, SP 01302-907 Brazil. \\ (55)(11)2114-8345, szpigel@ mackenzie.com.br \\ Eunézio A. de Souza \\ Photonics Laboratory, Universidade Presbiteriana Mackenzie, São Paulo, SP 01302-907 Brazil. \\ (55) (11)2114-8869, thoroh@mackenzie.br \\ Fábio Paschoal Jr. \\ Photonics Laboratory, Universidade Presbiteriana Mackenzie, São Paulo, SP 01302-907 Brazil. \\ (55) (11) 2114-8869, fabiopaschoaljr@yahoo.com.br \\ Erik A. Antonio \\ Photonics Laboratory, Universidade Presbiteriana Mackenzie, São Paulo, SP 01302-907 Brazil. \\ (55)(11)2114-8869,erik@uol.com.br \\ Joaquim P. Filho \\ Photonics Laboratory, Universidade Presbiteriana Mackenzie, São Paulo, SP 01302-907 Brazil. \\ (55)(11)2114-8869, joaquimpfilho@yahoo.com.br)
}

\begin{abstract}
The association of web technology with instrument automation and control has made possible the development of the so called Remote Laboratories or WebLabs - distributed environments that allow to access and control experiments remotely through the Internet - extending the interactivity in virtual learning environments to higher levels. In this work we describe the main characteristics of a WebLab developed for the remote measurement of an optical fiber's attenuation coefficient, which is part of an ongoing project whose goal is to implement a photonics remote laboratory aimed to support activities in face-to-face and online courses on optical communications. Preliminary tests on the overall performance of the system have shown very promising results, strongly indicating its potential as a sound and reliable tool for photonics education.
\end{abstract}

Index Terms - Attenuation Coefficient, Optical Fibers, Remote Laboratory, Virtual Learning Environment.

\section{Introduction}

The advent of the Internet generated new spaces for communication and collaboration between groups of people in geographically distributed areas. A wide variety of systems based on the web technology has been developed, integrating groupware tools and resources for synchronous and asynchronous communication.

In the educational scenario, these resources have been more and more used to implement on-line learning activities. The web incorporated the so called Learning Networks [1], allowing the creation of collaborative virtual learning environments where intense interaction occurs between teachers and students in the process of knowledge acquisition and construction.

The association of web technology with instrument automation and control has made possible the development of the so called Remote Laboratories or WebLabs - distributed environments that allow to access and control experiments remotely through the Internet - extending the interactivity in virtual learning environments to higher levels [2]. Several projects related to the automation and control of real experiments through the Internet have been developed, many focused on educational applications [3].

In this work we describe the main characteristics of a WebLab developed for the remote measurement of an optical fiber attenuation coefficient. This WebLab is part of an ongoing project, developed at the Mackenzie Photonics Laboratory, whose goal is to implement a photonics remote laboratory integrated to a virtual learning environment, aimed to support and complement activities in face-to-face and online courses on optical communications. 


\section{Structure of the WebLab}

The general structure of our WebLab is shown in Figure 1.

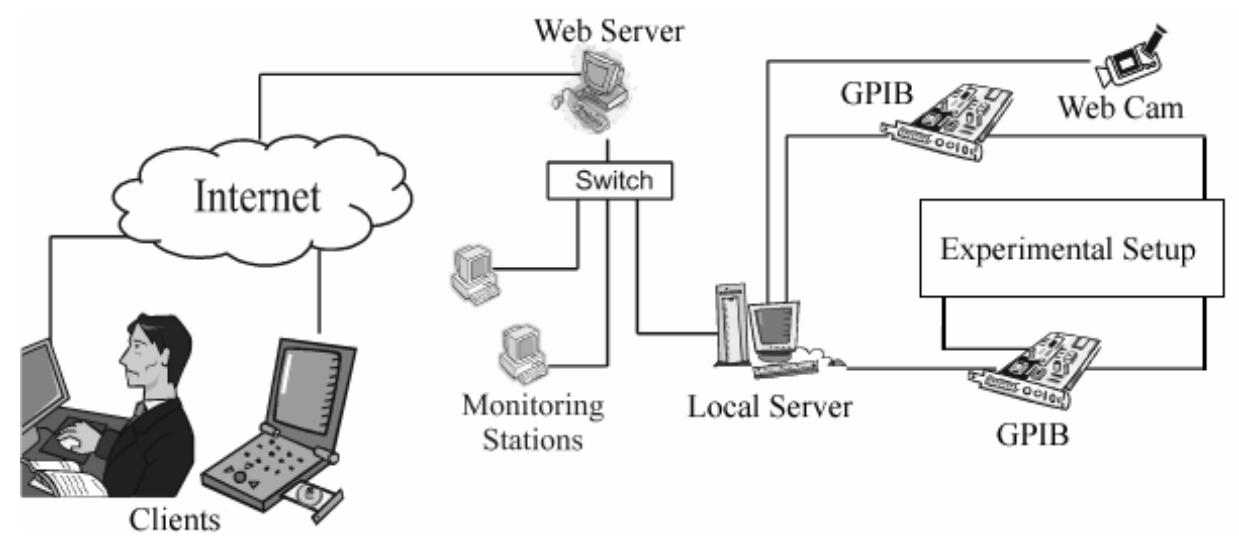

Fig. 1. General structure of the WebLab.

The automation of the experiment is implemented by connecting the instruments to a computer called Local Server via GPIB interfaces. A Switch is used to connect the Local Server to a computer called Web Server, responsible for the Clients access to the experiment through the Internet, and to local Monitoring Stations. Completing the system, a webcam is connected to the Local Server for real time instrument visualization and communication between users through videoconference, enhancing interactivity and the sensation of presence during the remote execution of the experiment.

In the system described above, instrument control and data acquisition from a computer called Local Server is performed through GPIB interfaces by using LabView Virtual Instruments (VI). Remote access and control of the experiment is implemented by employing a double client/server architecture [4], as shown in Figure 2.

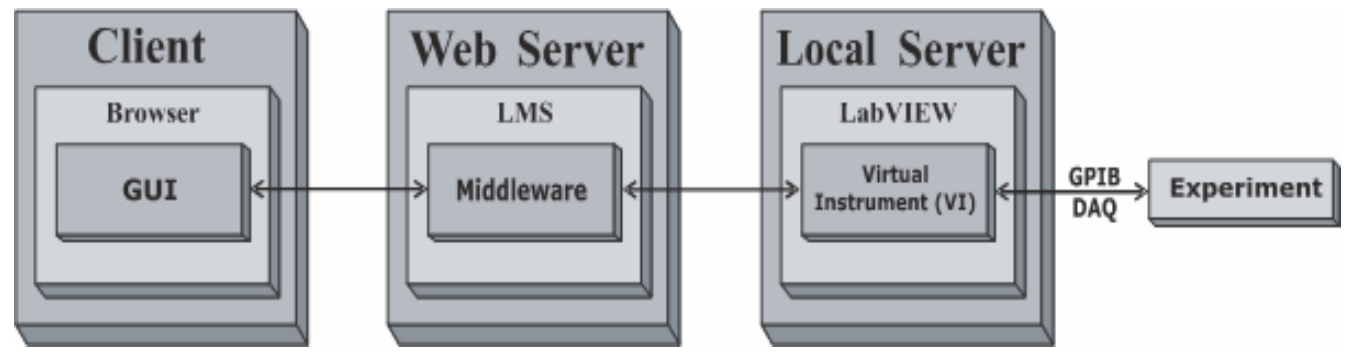

Fig. 2. Double client/server interface architecture.

In such architecture, the communication between the Client computers and the Local Server is mediated by computer called Web Server through a set of interface software applications, denoted by Middleware, embedded in a virtual learning environment.

The virtual learning environment is typically a set of integrated tools for user management, instructional content creation and management, on-line communication, assessment and activity tracking. The users access the virtual learning environment via the web browser and remotely control the experiment through a Graphic User Interface (GUI) which reproduces and executes the VI in the Client computers. 


\section{Experimental Setup}

The experiment chosen to implement the WebLab is the measurement of an optical fiber attenuation coefficient as a function of the injected laser signal wavelength, given by:

$$
\Gamma=-\frac{10}{z}\left[\log \left(\frac{P_{\text {out }}}{P^{\text {th }}}\right)\right],
$$

where $z$ is the fiber's length and $P_{\text {in }}$ and $P_{\text {out }}$ are respectively the input power and output power measured in Watts.

Our experimental setup, shown in Figure 3, is an adaptation of the traditional Cutback Method, which allows the measurement automation and remote control.

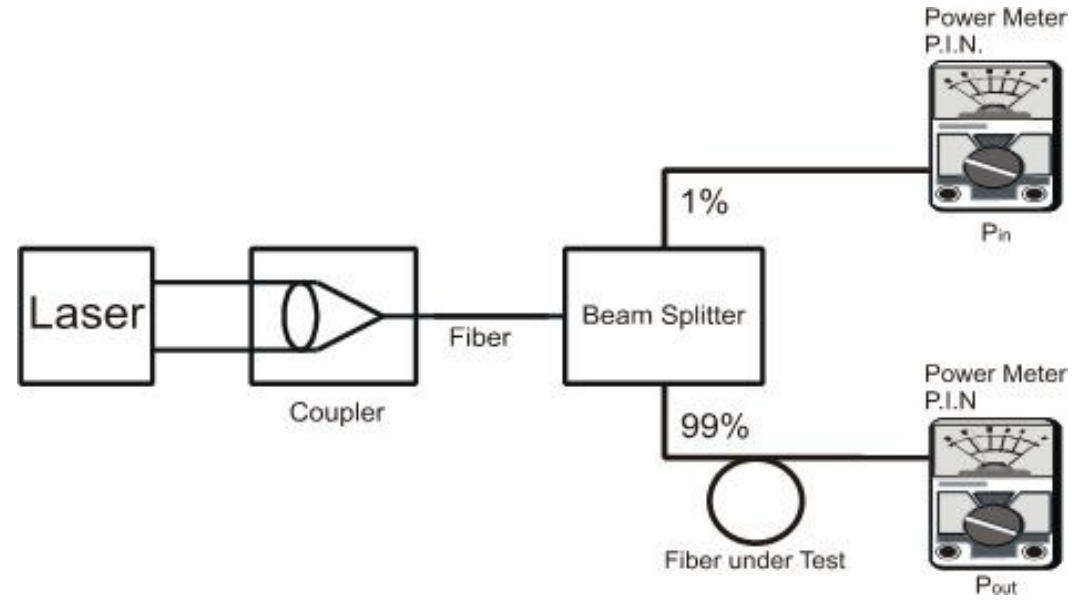

Fig. 3. Experimental setup for the remote measurement of an optical fiber attenuation coefficient.

Instead of cutting the fiber in order to measure the signal input power at each wavelength, as in the traditional Cutback Method, a beam-splitter is used to divide the signal in two parts, such that the input and output power can be simultaneously measured.

\section{Virtual Instruments}

In Figure 4 we show the Virtual Instrument Front Panel developed to control the experiment.

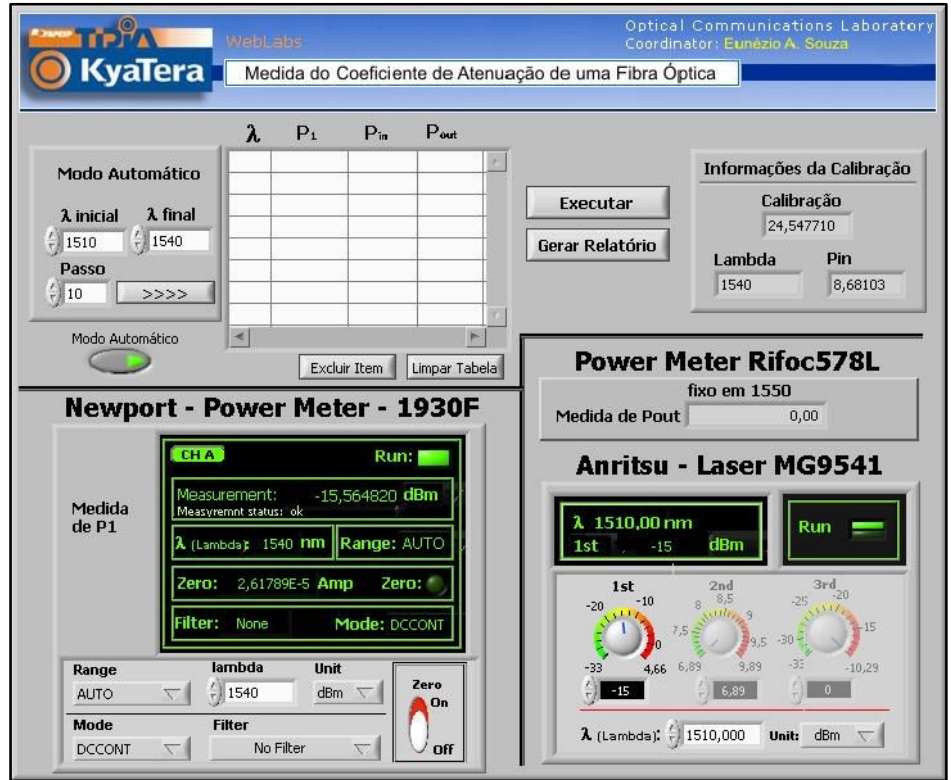

Fig. 4. VI Front Panel used to control the experiment. 
The panel on the bottom right allows the user to control the tunable laser:

- Select one of the three channels;

- Control the output power;

- $\quad$ Tune the wavelength;

- Choose the units to be displayed.

Just above, is a panel that allows the user only to monitor the power meter used to measure the output power.

The panel on the bottom left allows the user to control the power meter used to measure the input power:

- $\quad$ Select the channel, range, mode and filter to be used;

- Tune the wavelength;

- $\quad$ Choose the units to be displayed;

- $\quad$ Set the zero power reference.

The panel on the top is used to perform the experiment. The user can select the wavelengths and measure the corresponding input and output powers on the fiber under test one by one or run the experiment automatically, by pre-selecting a number of wavelengths within a given interval.

When the measurements are completed, the user can generate a report that shows the plot of the attenuation coefficient as a function of the wavelength, as shown in Figure 5.

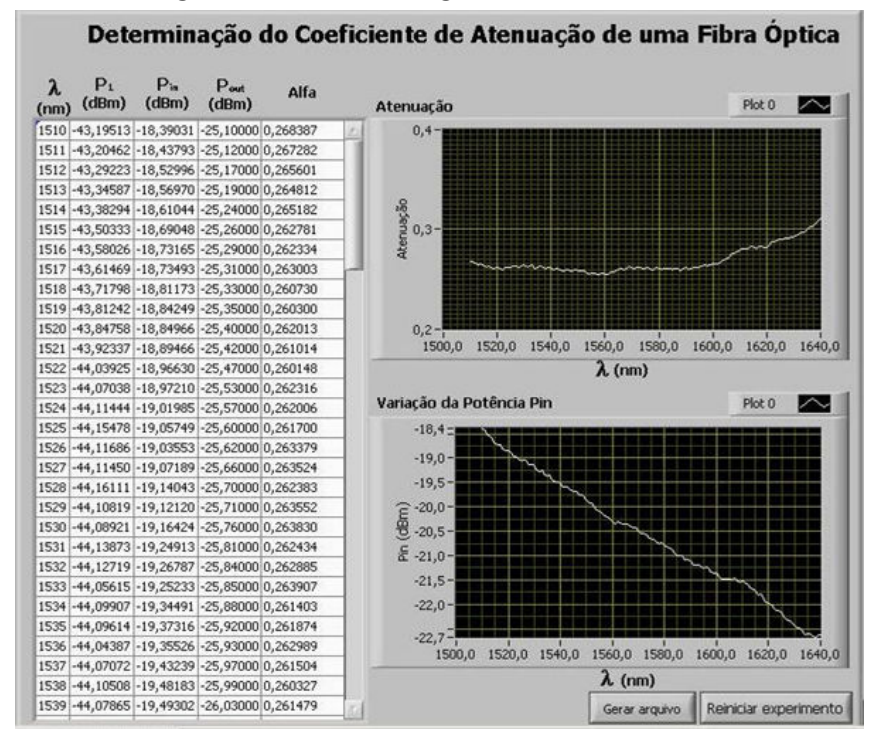

Fig. 5. VI Front Panel presenting the experiment results.

In Figure 6 we show the WebLab video interface, developed using a generic LabView webcam driver.

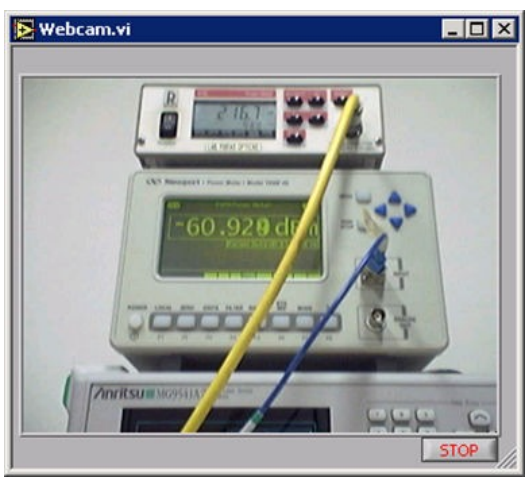

Fig. 6. WebLab video interface. 


\section{Integration to the virtual learning environment}

Our virtual learning environment is implemented with MOODLE (http://moodle.org), an open source PHP-based LMS freely distributed under the GNU Public License.

In order to integrate the WebLab to the virtual learning environment we developed a new application, called WebLab Module, using PHP scripts and original components from the MOODLE platform [5]. Currently, the WebLab Module includes functionalities for user management, registration of remote experiments and configuration of learning activities and assignments.

In Figure 7 we show the WebLab Module interface Description, which is the first one accessed by the students.

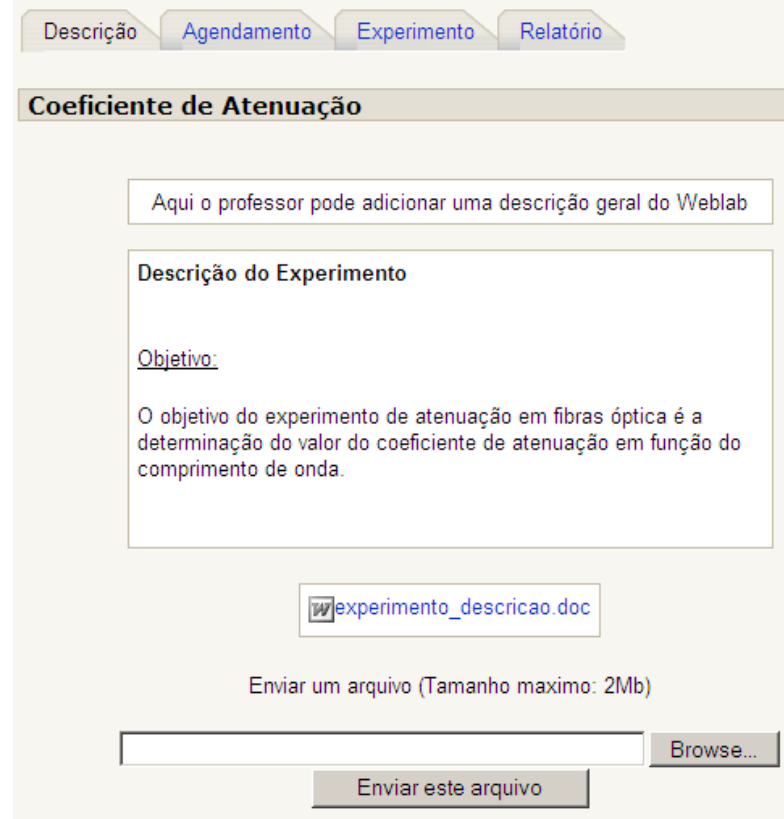

Fig. 7. Interface with the remote experiment description.

In Figure 8 we show the WebLab Module interface called Scheduling, used by the teacher to create the experiment's execution time slots when configuring a learning activity.

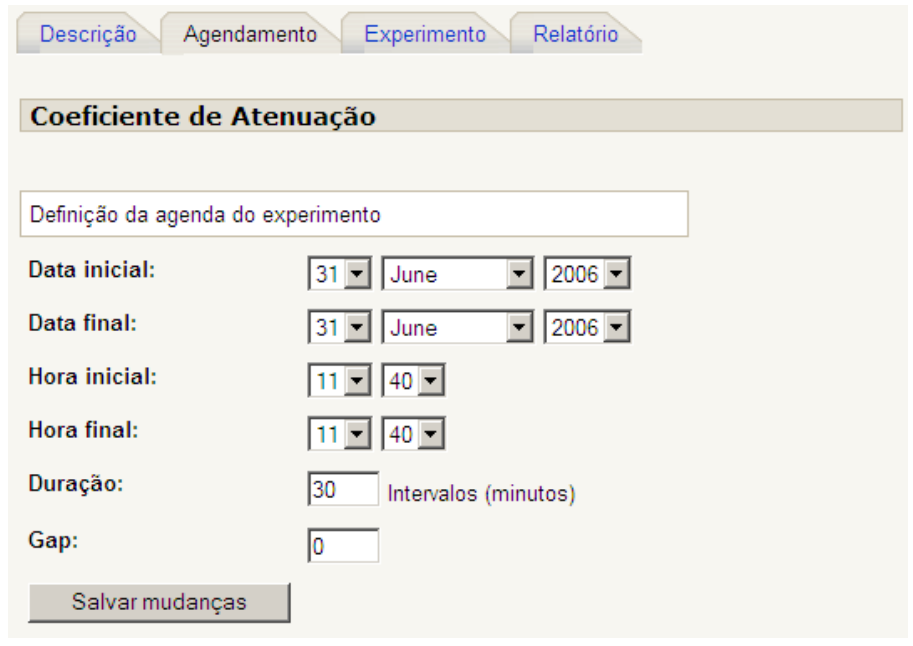

Fig. 8. Interface used to schedule execution time slots. 
In Figure 9 we show the WebLab Module interface used by the teacher to select a remote experiment.

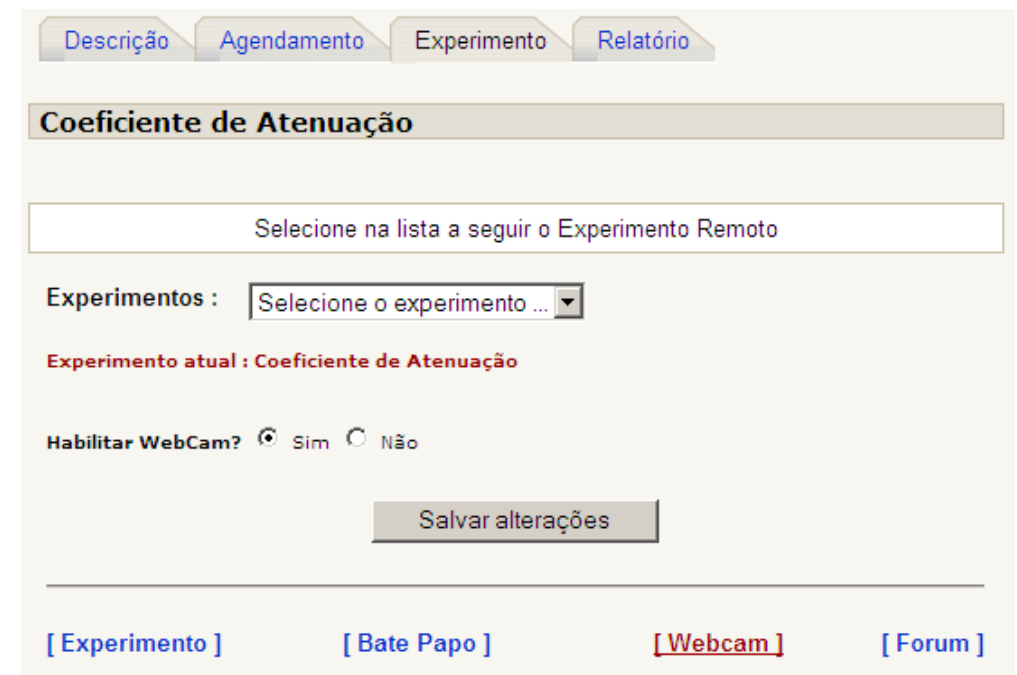

Fig. 9. Interface used to select a remote experiment.

\section{Final Considerations}

In this work we described the main characteristics of a WebLab for the remote measurement of an optical fiber's attenuation coefficient. One of the main features of the WebLab is the integration to a virtual learning environment implemented with MOODLE through a component called WebLab Module. At the present version, such component allows only for basic functionalities. A deeper integration will be further implemented with the development of Middleware components, based on message exchange via SOAP/XML protocol, to mediate communication between the Clients and the Local Server via the Web Server. Such components will allow the WebLab's adaptation within the virtual environment and transparency in remote calls of the experiment's control methods. We also intend to build a more efficient video component based on the framework JMF (Java Media Framework).

Preliminary tests on the overall performance of the system have shown very promising results, strongly indicating its potential as a sound and reliable tool for photonics education.

\section{Acknowledgements}

This work is supported by FAPESP through the TIDIA-KyaTera Project, Instituto Presbiteriano Mackenzie through MACKPESQUISA and CAPES.

\section{References}

[1] L. Harasim, R. Hiltz, L. Telles, and M. Turoff. Learning Networks: A Field Guide to Teaching \& Learning Online. Cambridge, MA: MIT Press, 1995.

[2] Z. Nedic, J. Machotka, and A. Nafalsky. Remote Laboratories versus Virtual and Real Laboratories. School of Electrical and Information Engineering, Mawson Lakes, 2003.

[3] Extensive list of WebLabs: [http://telerobot.mech.uwa.edu.au/links.html].

[4] S. H. Chen, R. Chen, V. Ramakrishnan, S. Y. Hu, Y. Zhuang, C. C. Ko, and B. M. Chen. "Development of Remote Laboratory Experimentation Through Internet", In Proc. of the 1999 IEEE Hong Kong Symposium on Robotics and Control, pp. 756-760, July 1999.

[5] F. Paschoal, Jr. Desenvolvimento de um WebLab para Experimentos Remotos em Fotônica Integrado a um Ambiente Virtual de Aprendizagem. Master Thesis, Programa de Pós-Graduação em Engenharia Elétrica, Universidade Presbiteriana Mackenzie, 2006. 